\title{
Passion fruit (Passiflora edulis) peel powder extract and its application towards antibacterial and antioxidant activity on the preserved meat products
}

\author{
Aizi Nor Mazila Ramli ${ }^{1}$ (D Nor Wansuhada Abdul Manap ${ }^{1} \cdot$ Prakash Bhuyar $^{2} \cdot$ Nur Izyan Wan Azelee $^{1,3}$
}

Received: 16 April 2020 / Accepted: 17 September 2020 / Published online: 30 September 2020

(c) Springer Nature Switzerland AG 2020

\begin{abstract}
This study aimed to explore the antioxidant and antibacterial compounds in $P$. edulis peels and to identify the effectiveness of $P$. edulis peels extract on preserved meat. In this research studies, the antioxidant compound from sample extract of $P$. edulis peel is determined using total flavonoid and total phenolic content respectively. TPC of $7.273 \pm 0.002 \mathrm{mg}$ GAE/g extract was detected while TFC of $8.364 \pm 0.002 \mathrm{mg}$ QE/g extract was found significantly. LC-QTOF_MS confirmed the phenolic compounds in the $P$. edulis extract. Antibacterial ability of sample extract is proven by inhibition zone observed in agar plate that containing four types of foodborne pathogen extract exerted a strong antibacterial activity against three tested strains which were E. coli, Serratia and Aureus. The effectiveness of sample extract on meat antioxidant is determined using DPPH when percentage of scavenging activity up to $13 \%$, ABTS with $60 \%$, reducing power assay with $48 \%$ and metMY reach maximum percentage which is $70 \%$ at day 6 . The $\mathrm{pH}$ value of marinated meat with sample extract indicated that the meat is safe and not required immediate consumption after 9 days. In conclusion, $P$. edulis peels extract can be considered as a natural antioxidant and antibacterial on meat as well as food preservative for frozen meat.
\end{abstract}

Keywords Antioxidant $\cdot \mathrm{DPPH} \cdot$ Meat $\cdot$ Passion fruit peels

\section{Introduction}

Meat, the muscle tissue of slaughter animals, is an indispensable source of nutrients in human diet and are consumed in massive amounts in developed and modern societies. Meat composed of water, proteins, lipids, essential amino acids and a small proportion of minerals, vitamins and carbohydrates [1,2]. The composition of meat can vary among different sources of animal and also the diet of the animal [3]. Meat and meat products are susceptible to quality deterioration due to the prooxidant substances in meat like polyunsaturated fatty acids (PUFA), cholesterol, proteins and pigments which are susceptible to oxidation
$[4,5]$. However, the major form of chemical deterioration is contributed by lipid oxidation that often occur during processing and storage [6]. Oxidative degradation of lipids can be delay or suppressed by the use of antioxidants in meat and meat products and thus improve quality, nutritional value and shelf-life [7].

Synthetic antioxidants such as butylated hydroxyanisole (BHA), butylated hydroxytoluene (BHT), tertbutylhydroquinone (TBHQ), and propyl gallate (PG) have been extensively used in meat and poultry products to uphold the safety and prolong the shelf-life of meat and meat products [8]. These synthetic antioxidants are used to control the lipid oxidation and to eliminate bacteria or

Aizi Nor Mazila Ramli, aizinor@ump.edu.my | ${ }^{1}$ College of Computing and Applied Sciences, Faculty of Industrial Sciences and Technology, Universiti Malaysia Pahang, Lebuhraya Tun Razak, Gambang, 26300 Kuantan, Pahang, Malaysia. ${ }^{2}$ School of Renewable Energy, Maejo University, Chiang Mai 50290, Thailand. ${ }^{3}$ Bio Aromatic Research Centre of Excellence, Universiti Malaysia Pahang, Lebuhraya Tun Razak, Gambang, 26300 Kuantan, Pahang, Malaysia. 
moulds. Though they are both powerful and inexpensive, synthetic antioxidants are suspected causing toxicological effects and consumer concern has led to a lessening in their usage in the food industry [9]. Thus, directing at the decreasing of the consumption of synthetic chemical compounds that may impair the consumer's health and well-being has created demand for natural antioxidants by consumers and the meat industry.

In this manner, natural antioxidants from plants extract can be used as alternatives to synthetic antioxidants owing to their comparable or superior effect on the inhibition of lipid oxidation and bacterial growth [10]. The use of natural antioxidants in the food industry was preferable as natural products do not necessitate comprehensive safety testing prior to use. These natural antioxidants from plants include lotus [8], oregano, sage [11], black pepper, rosemary $[12,13]$ green tea and grape seed [14]. However, natural antioxidants are often more expensive than synthetic antioxidants. As a consequence, many attention has been focused on the extraction of antioxidants from cheap materials or residual sources from agricultural processing industries for example potato peel [15], citrus by-product including pulp, peel and seeds [16] and carrot residues [17].

Meat industry is recommending to severe natural bases to exchange synthetic to be antioxidants because of the harmful health significances concerning some synthetic ones. Plants resources offer good replacements [18]. The use of food and vegetables by-product as a natural food addictive has been encouraged due to their richness in polyphenols [7]. The effectiveness of natural antioxidants depends on conditions such type of meat, type of fat and other ingredients. Passion fruit background is belongs to Passifloraceae family and their formerly from American tropical [19]. Researchers, proved that this interesting fruit are rich with vitamin $A$ and also $C$, carotenoid and some polyphenols [20].

The passion fruit is the fruit of any variety of the species Passiflora edulis, the main characteristic is the ovoid shape and the yellow skin [21]. This fruit, 38\% of the fruit corresponding to the pulp with the seed is used and the other $62 \%$ corresponds to the peel. The passion fruit possesses antifungal and antibacterial activity against fungi and bacteria which cause infectious diseases in human and plants [22]. In a previous study, demonstrated the antioxidant and antimicrobial activities of passion fruit seed and seed cake extracts obtained by different methods and solvents [23]. Natural antioxidants and antimicrobials are an excellent way to improve food quality and shelf-life without introducing undesirable chemical preservatives. These materials can also be useful for cosmetics and pharmaceutical products; however, exposure to oxygen, heat and light can cause loss or reduction of extract's bioactivities.
Thus, co-precipitation with polymers may be used to preserve active compounds [23].

In this research study, $P$. edulis peels was extracted and apply on meat to see the effectiveness of their compound contain in peels as antioxidant and antimicrobial. The broad objective of this research to see the effectiveness natural residual on meat can be determined through some method including through the DPPH analysis. In this research also it involves the use of fruit waste as antioxidant and antimicrobial on meat. Even though the synthetic additives have been commonly used in the meat industry to prevent both of the process of lipid oxidation and microbial growth, but the more concern to consumer is about the chemical that can cause harmful effect. The main objective of this research was to identify antioxidant and antibacterial compounds in Passiflora edulis peels and to identify the effectiveness of Passiflora edulis peels extract as antioxidant and antimicrobial on meat.

\section{Materials and methods}

\subsection{Preparation of the extracts}

Passiflora edulis was purchased from nearby supermarket were rinse, cut into half, pulp and seeds was detached from the fruit [24]. The peels were submerged in water for $3 \mathrm{~min}$ and followed with stored at refrigerator for next used. Two method of extraction is performed where P. edulis peel is washed and left to dried follow with grinding to be obtained fresh sample. Peels with $50 \mathrm{~g}$ were grind with $150 \mathrm{~mL}$ of distilled water equal to 1:3 ratio until produce the peel juice and continue with filtration [25]. Another one method is by submerged the $P$. edulis peel with ratio $1: 3$ which is $100 \mathrm{~g}$ of peel with $300 \mathrm{~mL}$ of distilled water overnight. After $24 \mathrm{~h}$, the sample was filtered using Whatman No.1 filter paper and continued with rotary evaporator for $4 \mathrm{~h}$.

\subsection{Determination of total flavonoid and phenolic in the extract}

Total flavonoid content (TFC) of $P$. edulis peel extract were determined by colorimetric assay. A standard curve was generated with rutin as the reference compound, flavonoid concentrations were calculated from the calibration curve and the regression equation, results were plot and expressed in amount of milligrams of quercetin equality in per gm of sample [24]. Total phenolic content (TPC) of $P$. edulis peel extract was determined using the Folin-Ciocalteau assay. Phenolic concentrations were calculated from the calibration curve and the regression equation, results 
were plot and expressed in number of milligrams of gallic acid equality per gram of sample.

\subsection{LC-QTOF MS analysis}

The phenolic and flavonoid content in extract of $P$. edulis peels was characterized using LC-MC-QTOF. Phytochemical profile was identified using an Agilent Technologies 6530 OHD Accurate-Mass Q-TOF MS/MS system (Agilent Technologies, CA, Santa Clara, USA) equipped with an Agilent 1290 UPLC system and an ESI source. Identification of each compounds was carried out by analysing the precursor ion, molecular weight, fragmentation pattern, retention time, and by matching these data with that reported in available references. Constituent separation was done using $0.1 \%$ formic acid in water and acetonitrile as the mobile phase. The sample injection volume was $0.5 \mu \mathrm{L}$ while the flow rate was $0.5 \mathrm{~mL} / \mathrm{min}$. The analysis was performed in negative ion modes for phenolic and flavonoids respectively, with an interface voltage $2.50 \mathrm{kV}$, temperature $120^{\circ} \mathrm{C}$. Automatic MS/MS experiment was performed by adjusting the collision energy as follows: $\mathrm{m} / \mathrm{z}<200,10$, $20 \mathrm{eV} ; \mathrm{m} / \mathrm{z}$ 200-400, 20, $30 \mathrm{eV} ; \mathrm{m} / \mathrm{z}$ 400-600, 30, $40 \mathrm{eV}$; $\mathrm{m} / \mathrm{z}>600,40,50 \mathrm{eV} ; \mathrm{m} / \mathrm{z}>700,40,50,60 \mathrm{eV}$. The MS data were processed with Mass Hunter software (Agilent Technologies, CA, Santa Clara, USA). The compound was identified based on their times and MS spectra as compare to authenticated standard [26].

\subsection{Preparation of meat samples}

Meat was adequately supplied through the purchase of a nearby supermarket where the meat without fat was stored in a cool place for freezing. The meat was separated into two groups which are for control and sample. Both types of meat in each group have the same weight as $30 \mathrm{~g}$ meat. Meat in the sample group was immersed in $6 \% \mathrm{w} / \mathrm{w}$ of $P$. edulis peel extract according to method described [8] with slightly modifications the concentration of extract. Meanwhile, the control group not treated with extract or any substance. Both sample and control were stored before ready to be tested for day 0 , day 3 , day 6 and day 9 .

\subsection{Preparation of meat agar}

Ten grams of meat without any fat were added to $90 \mathrm{~mL}$ of buffered peptone water and blended until it smoothed. After that, the sample were centrifuged to obtain the supernatant or the clarified extract by removed the solid particle. The final solid media with $1.5 \%$ agar was prepared until $1000 \mathrm{~mL}$. Finally, prepared meat agar solution were autoclaved at $121{ }^{\circ} \mathrm{C}$ for $15 \mathrm{~min}$ prior to use to eliminate contamination from others organism that may present in the food [27].

\subsection{Antibacterial testing}

Antibacterial activity of Passiflora edulis peels was determined by the agar diffusion method [27-29]. The inoculum of bacteria was prepared by touch four or five isolated colonies in $2 \mathrm{~mL}$ of sterile saline water. The turbidity of inoculum suspension was adjusted to a 00.5 McFarland standard by added more colonies if the inoculum suspension was too light or diluted it saline water if the turbidity was too heavy. Impregnated of sterile paper disk ( $6 \mathrm{~mm}$ in diameter) with $30 \mu \mathrm{L}$ of $P$. edulis peels extract and left it until the disk can really absorb the peel extract [30]. Distilled water is used as negative control, ampicillin as positive and then plates were left for $15 \mathrm{~min}$ in room temperature to allow the diffusion of the extract and were incubated at $37^{\circ} \mathrm{C}$ for each bacterium for $24 \mathrm{~h}$.

\subsection{DPPH free radical scavenging activity}

Free radical scavenging activity was evaluated by the DPPH assay using the standard method [8]. Meat with $0.03 \mathrm{~g}$ weight were continuously mixed with $3 \mathrm{~mL}$ of $0.004 \%$ DPPH that has been prepared using methanol in a test tube at room temperature for $30 \mathrm{~min}$. The samples were centrifuged at $1430 \times g$ for $10 \mathrm{~min}$. By using methanol as blank, absorbance of the supernatants was measured at $517 \mathrm{~nm}$. Measurements were expressed as absorbance and decreasing values indicated increasing antioxidant activity [8].

\subsection{ABTS free radical scavenging activity}

Antioxidant activity of the samples was also measured using an improved ABTS (azinobisethylbenzthiazolinesulfonic acid) procedure [7, 31]. The ABTS radical cation (ABTS+) solution was prepared through the reaction of $7 \mathrm{mM} \mathrm{ABTS}$ and $2.45 \mathrm{mM}$ potassium persulphate, after incubation in a dark for $16 \mathrm{~h}$ at room temperature. The ABTS+ solution was then diluted with $80 \%$ ethanol to obtain an absorbance of $0.700 \pm 0.005$ at $734 \mathrm{~nm} .3 \mathrm{~mL}$ of ABTS solution at absorbance $0.700 \pm 0.005$ was added to $0.03 \mathrm{~g}$ of the samples and mixed vigorously. Allowed this mixture to stand at $30^{\circ} \mathrm{C}$ for $30 \mathrm{~min}$ before centrifugation at $1430 \times g$ for $10 \mathrm{~min}$. The supernatant's absorbance at $734 \mathrm{~nm}$ was immediately recorded. Lower absorbance levels indicated higher antioxidant activity. 


\subsection{Reducing power assay}

Meat samples with $0.03 \mathrm{~g}$ were mixed with $2.5 \mathrm{~mL}$ of $200 \mathrm{mM}$ sodium phosphate buffer ( $\mathrm{pH} \mathrm{6.6)}$ and $2.5 \mathrm{~mL}$ of $1 \%$ potassium ferric cyanide followed with incubated at $50{ }^{\circ} \mathrm{C}$ for $20 \mathrm{~min}$. Next steps are $2.5 \mathrm{~mL}$ of $10 \%$ trichloroacetic acid $(\mathrm{w} / \mathrm{v})$ was added before the mixture was centrifuged at $1430 \times g$ for $8 \mathrm{~min}$. Deionized water was added with equal volume of resulting supernatant and $1 / 5$ volume of $0.1 \%$ ferric chloride. After $10 \mathrm{~min}$, the absorbance of the resulting solution was measured at $700 \mathrm{~nm}$. Increased absorbance of the reaction mixture indicated increased reducing power [8].

\subsection{Measurement of metmyoglobin (metMY)}

Briefly, a portion $(0.5 \mathrm{~g})$ of meat was homogenized with $3 \mathrm{~mL}$ of cooled $\left(4^{\circ} \mathrm{C}\right) 0.04 \mathrm{M}$ phosphate buffer at $\mathrm{pH} 6.8$. The mixture was kept at $4{ }^{\circ} \mathrm{C}$ for $1 \mathrm{~h}$ and subsequently centrifuged at $2240 \times g$ for $5 \mathrm{~min}$. Metmyoglobin (metMb) accumulation in meat was measured by spectrophotometrically as described by Huang et al.,2010 [32]. The supernatant resulted from centrifuge was filtered and metMb formation was estimated from the absorbance at $503 \mathrm{~nm}$.

\section{$2.11 \mathrm{pH}$ determination}

To measure $\mathrm{pH}, 0.5 \mathrm{~g}$ samples were homogenized with $3 \mathrm{~mL}$ of distilled water and the homogenate was centrifuged at $2240 \times g$ for $5 \mathrm{~min}$. The supernatant was filtered, and the $\mathrm{pH}$ of the supernatant measured using $\mathrm{pH}$ meter (Biomed, UK) [26, 33, 34].

\subsection{Statistical analysis}

All the resulted data (mean values) were statistically analysed with the SPSS analysis of variance (SPSS version 12.0 for Windows, SPSS Inc., Chicago, IL, USA). Duncan's multiple range test was used for the study of studentized range distribution in order to determine critical values for comparisons between means. The significance for all comparisons was determined at the $P<0.05$ level.

\section{Results and discussion}

\subsection{Total flavonoid and total phenolic analysis in extracts}

Flavonoid and phenolics in some plant were depended to maturity and some environmental factor such as nutrition, temperature, and water availability. In this research, total flavonoid content in passion fruit peels were obtained with quercetin as standard. Quercetin was found in various food products and plants. The reason quercetin used as standard because quercetin is a member of a group of naturally occurring compounds which is flavonoids [35]. It also mentioned that quercetin was a strong antioxidant due to its ability to scavenge free radicals and bind transition metal ions. These properties of quercetin allow it to inhibit lipid peroxidation. In the measurement, sample solution was added with $\mathrm{AlCl}_{3}$ where $\mathrm{AlCl}_{3}$ can convert into complex form so that a wavelength switch towards visible range marked with solution produce more yellow colour.

Table 1 shows the value of absorbance for triplicate reading each method. From the means, the results were derived from the calibration curve $(y=0.0946 x+0.3072, R 2=0.9757)$ and expressed in quercetin equivalents (QE) per gram sample (Table 1). Higher value of flavonoid content $(0.3161 \mathrm{mg}$ quercetin equivalent per $\mathrm{g}$ sample) was obtained from rotary evaporator extraction method. On the other studies stated that the total flavonoid content in passion fruit peel from freeze dried method is $0.59 \pm 0.05$ [35]. The values obtained from these studies was different with may be due to the method used since freeze dried method will extract more compound in peels than rotary evaporator [23].

Total phenolic content of passion fruit peel was obtained by $10 \%$ Follin Ciocalteu reagent with gallic acid as a standard. Gallic acid is one of natural phenol compound that derived from hydro-benzoic acid and it was reacted with Follin Ciocalteu in an alkaline condition. Hydroxyls group that contained in phenolic compound will react with gallic acid during the reaction. Total Phenolic content were expressed as gallic acid per gram sample. Gallic acid was used as a traditional antioxidant agent. Gallic acid has high oxygen derived free radical scavenging activity due to the presence of polyphenolic functionality. It prevents the rancidity and spoilage of fats and oils due to its antioxidant nature facilitating its application as food additives in various eatable materials [31].

Table 1 shows the value of absorbance for triplicate reading each method. From the means, mg gallic acid equivalent per $g$ sample was obtained from calculation with equation from standard graph which was $(y=0.0799 x+0.1551)$. The value of $\mathrm{mg}$ gallic acid equivalent per $\mathrm{g}$ sample was higher from rotary evaporator method with 1.891. The low TPC in $P$. edulis peel extract has proven that the peel extract should be containing another phytochemical besides phenolic compound [21]. Antioxidant not only contributed by phenolic

Table 1 Total flavonoid and phenolic in P. edulis peels extracts

\begin{tabular}{lll}
\hline Method of extract & TFC $(\mathrm{mg} / \mathrm{g})$ & TPC $(\mathrm{mg} / \mathrm{g})$ \\
\hline Rotary evaporator & $8.364 \pm 0.002$ & $7.273 \pm 0.002$ \\
Fresh & $4.241 \pm 0.007$ & $4.782 \pm 0.005$ \\
\hline
\end{tabular}


compound but also from other compound such ascorbic acid, tocopherols and others. The total phenolic content obtained from the freeze-dried method was $6.47 \pm 0.21$. The different in extraction method lead to different value of total phenolic content [23].

\subsection{LC-QTOF-MS}

LC-QTOF-MS was done to further identifying the specific of flavonoid and phenolic compounds present in P. edulis peels extracts. Some of compound were identified in
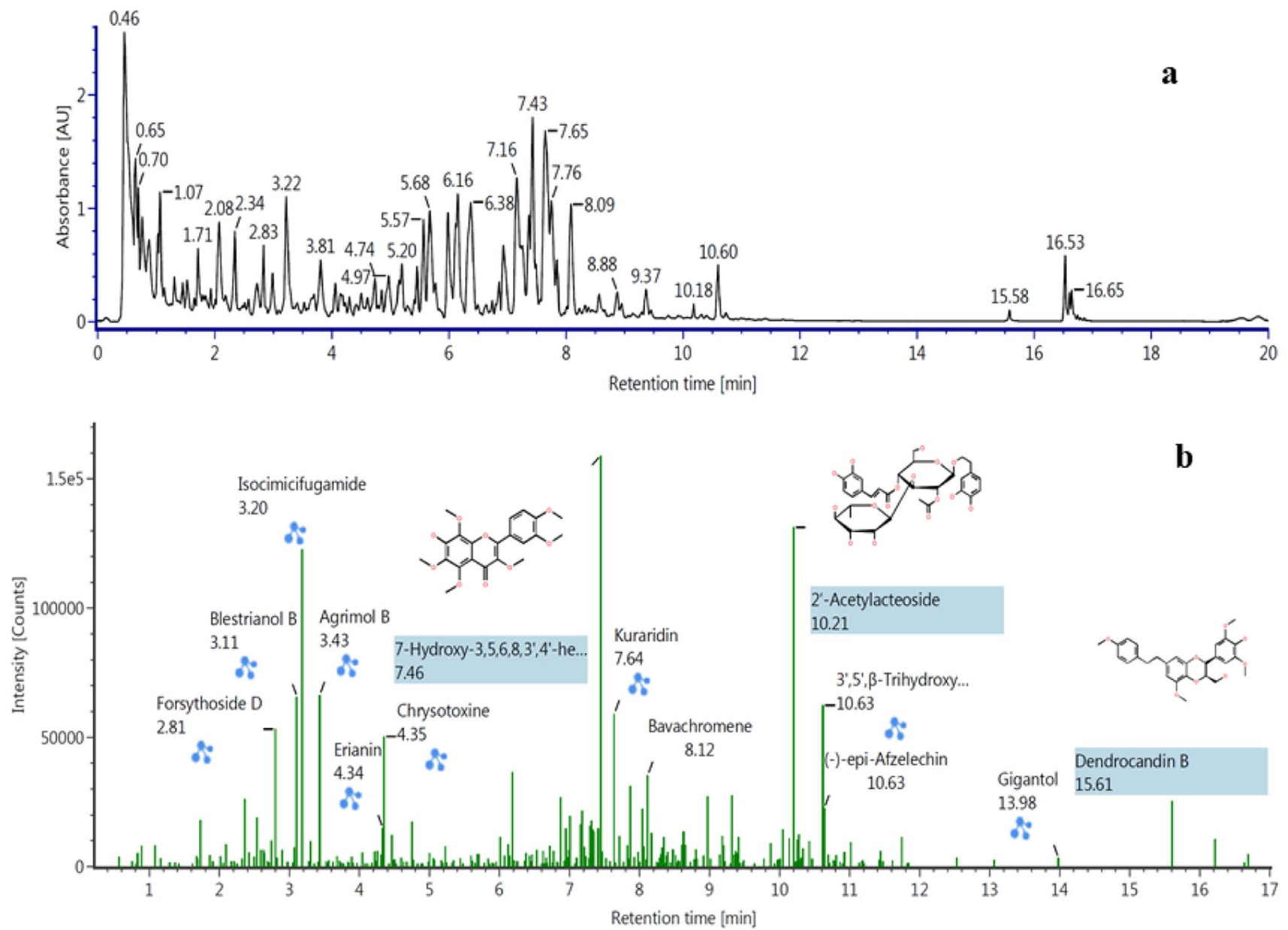

Fig. 1 LC-QTOF-MS a PDA analysis spectra b MS spectra analysis of $P$. edulis peels extracts

Table 2 LC-QTOF-MScompounds identified by MS spectra analysis of $P$. edulis peels extracts

\begin{tabular}{llllll}
\hline Component name & $\begin{array}{l}\text { Neutral mass } \\
(\mathrm{Da})\end{array}$ & Observed m/z & $\begin{array}{l}\text { Observed } \\
\mathrm{RT}(\mathrm{min})\end{array}$ & $\begin{array}{l}\text { Observed } \\
\text { drift (ms) }\end{array}$ & Observed CCS $\left(\AA^{2}\right)$ \\
\hline Psorachalcone A & 340.1312 & 341.1385 & 16.63 & 5.75 & 186.87 \\
Kushenol I & 408.1953 & 409.2025 & 16.7 & 6.69 & 211.41 \\
Neokurarinol & 470.2294 & 471.2367 & 18.59 & 6.93 & 217.99 \\
5,7,4'-Trihydroxy-8,3'- & 406.1812 & 429.1704 & 16.63 & 6.77 & 213.64 \\
$\quad$ diprenylflavone & & & & & \\
Kuwanon S & 406.1812 & 429.1704 & 16.63 & 6.77 & 213.64 \\
$\begin{array}{l}\text { (2S)-3',4'-Methylenedioxy-5,7- } \\
\text { dimethoxyflavane }\end{array}$ & 314.1164 & 337.1056 & 16.69 & 5.5 & 180.47 \\
3'-Deoxysappanone B & 314.1164 & 337.1056 & 16.69 & 5.5 & 180.47 \\
Mulberrofuran A & 392.2023 & 393.2096 & 6.15 & 5.56 & 181.66 \\
Gigantol & 260.1026 & 261.1099 & 13.98 & 4.78 & 163.22 \\
Dendrocandin B & 482.1983 & 483.2056 & 15.61 & 8.43 & 261.2 \\
Dendrocandin B & 482.1983 & 483.2056 & 15.62 & 6.43 & 204.44 \\
\hline
\end{tabular}


this extract as shown is Fig. 1 and Table 2 such as Dendrocandin B (15.61), 7-Hydroxy-3, 5, 6, 8, 3', 4'-hexamethoxyflavone (7.46) and 2'-Acetylactoside (10.21) were shown highest intensity. These identified compounds represent phenolic and flavonoid group. P. edulis peels contains antioxidant compound such as Meliadanoside A from phenolic group and 7-Hydroxy-5,3,4,'-trimethoxyflavone from flavonoid group.

Table 3 Antibacterial activity of Passiflora edulis peels against several bacterial strain using meat extract as culture medium

\begin{tabular}{|c|c|c|c|c|}
\hline & \multicolumn{4}{|c|}{$\begin{array}{l}\text { Diameter of inhibition zone }(\mathrm{mm}) \text { including disc } \\
(6 \mathrm{~mm})\end{array}$} \\
\hline & E. coli & $\begin{array}{l}\text { S. marces- } \\
\text { cens }\end{array}$ & P. vulgaris & S. aureus \\
\hline $\begin{array}{l}\text { Negative } \\
\text { Control } \\
\left(\mathrm{dH}_{2} \mathrm{O}\right)\end{array}$ & $(-)$ & $(-)$ & $(-)$ & $(-)$ \\
\hline $\begin{array}{l}\text { Positive } \\
\text { control } \\
\text { (ampicil- } \\
\text { lin) }\end{array}$ & $30 \pm 2.51^{(+++)}$ & $26 \pm 1.15^{(++)}$ & $(-)$ & $27 \pm 1.52^{(++)}$ \\
\hline $\begin{array}{l}\text { Peel extract } \\
\text { disk } 1\end{array}$ & $13 \pm 1.52^{(-)}$ & $17 \pm 0.57^{(+)}$ & $(-)$ & $21 \pm 1.73^{(++)}$ \\
\hline $\begin{array}{l}\text { Peel extract } \\
\text { disk } 2\end{array}$ & $10 \pm 1.15^{(-)}$ & $14 \pm 0.57^{(+)}$ & $(-)$ & $21 \pm 1.15^{(++)}$ \\
\hline
\end{tabular}

\subsection{Antibacterial activity}

The antibacterial of Passiflora edulis peels extract was determined by the application of disk diffusion against four types of bacteria that commonly involved with refrigerated food pathogenicity [31]. Table 3 shows the antibacterial of passion fruit peels using meat extract as culture medium. The results obtained from the disc diffusion method indicated that $P$. edulis peels extract exerted a strong antibacterial activity against three tested strains which were E. coli, Serratia and Aureus. But, one of the bacteria which is Vulgaris didn't showed any effect when there was no inhibition zone occur so it could consider that antibacterial passion fruit peels extract was not suitable to against this type of bacteria. The largest clearance of inhibition zone from peel extract is Aureus species. In Table 3 above showed $p$ value between all types of bacteria is $(P>0.05)$. All types of bacteria used was bacteria that involved and causes of food poisoning.

Proteus Vulgaris had an extra cytoplasmic outer membrane. Studies on microbiology of $P$. vulgaris mentioned that $P$. vulgaris not limited to any specific temperature range, but good growth occurs at 20 and $30^{\circ} \mathrm{C}$, while growth is poor at $37^{\circ} \mathrm{C}$ [36]. In this research, the failure of inhibition zone occur was possibility due to the temperature used was $35^{\circ} \mathrm{C}$ is still good enough environment for $P$. vulgaris to grow against the extract of $P$. edulis peel extract. The other feature was that $P$. vulgaris could produce urease and degrade urea to ammonia so by alkalinizing the urine,
Fig. 2 Zone of inhibition of Passiflora edulis peels against a Aureus, b E. coli, c Serratia and $\mathbf{d}$ Vulgaris bacterial strain using meat extract as culture medium (Amersham Imager 680)

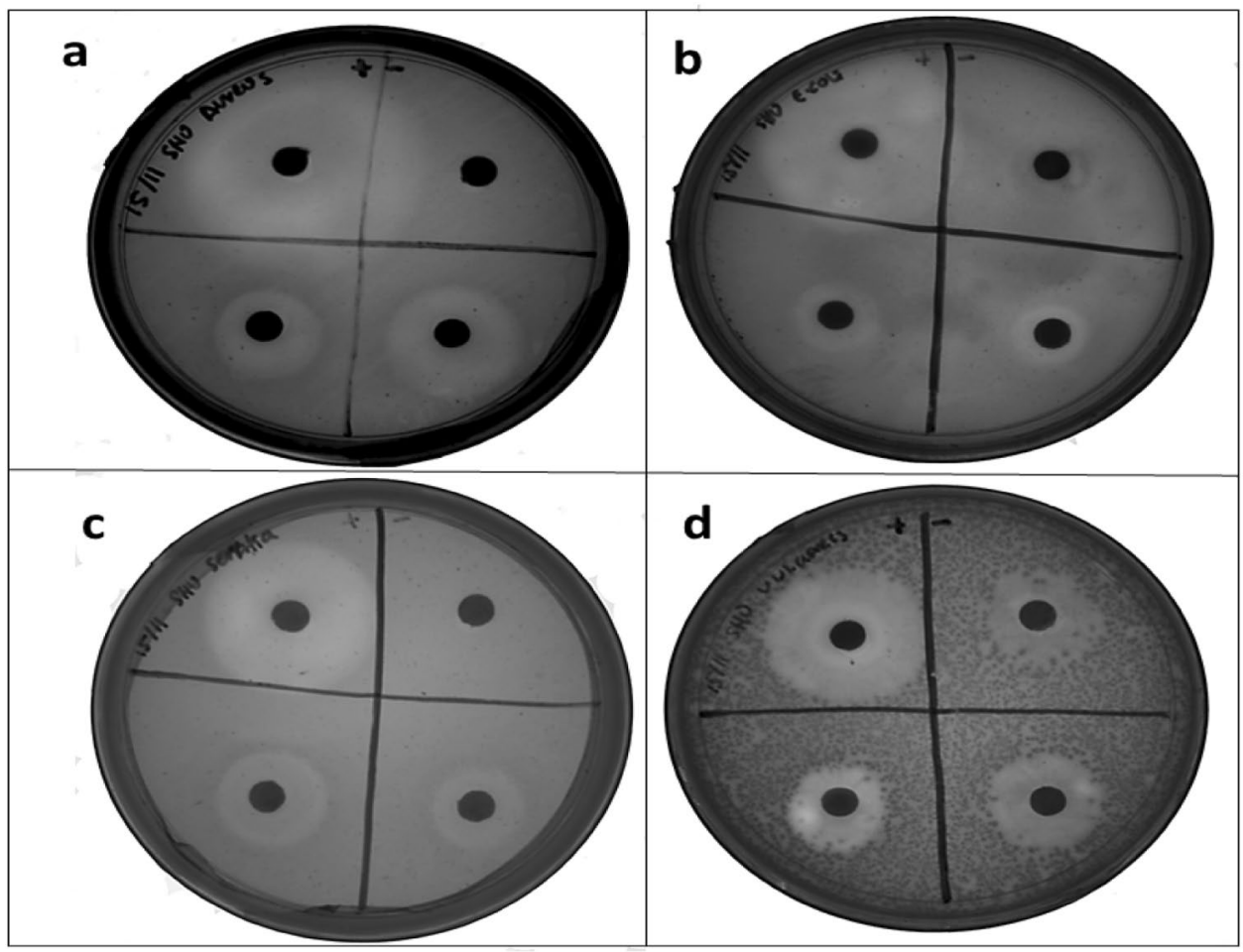


P. vulgaris made the environment more suitable for its survival [36]. From the antibiotic therapy of $P$. vulgaris species were highly resistant to antibiotics. The Fig. 2 is taken using Amersham Imager 680 in black and white color because the unclear of inhibition zone in usual color view.

\subsection{DPPH and ABTS free radical scavenging activity analysis}

The antioxidant activities of $P$. edulis peel on meat was determined through the DPPH free radical scavenging activities assay. This analysis involved the observation and reading based day for 9 days. Table 4 showed the triplicate reading of absorbance for each day at day 0 , day three, day six and day nine. Mean value was calculated to obtain the average from triplicate reading. Decreasing value of absorbance indicated the increasing of antioxidant activities. Based on Fig. 3, at first 3 days, value for marinated sample showed the highest DPPH radical activities at absorbance 0.264 for average. On day 9 , the absorbance value of DPPH Radical scavenging activities of marinated sample was significantly decreased to 0.252 . Control sample at day 9 became the highest value among the all reading. This bar graph indirectly shows there were antioxidant activities from Passiflora edulis peel extract. On the other hand DPPH offered a convenient and accurate method for titrating the oxidizable groups of natural or synthetic antioxidants [37]. Based on Fig. 3, the percentage of DPPH activity of marinated sample in peels increase from day 3 to day 9 .

Table 4 Percentage of DPPH and ABTS free radical scavenging activity in 9 days analysis

\begin{tabular}{lllcl}
\hline Analysis & \multicolumn{4}{l}{ Percentage of free radical scavenging activity (\%) } \\
\cline { 2 - 5 } & Day 0 (\%) & Day 3 (\%) & Day 6 (\%) & Day 9 (\%) \\
\hline DPPH & 4.28 & 4.35 & 6.41 & 13.4 \\
ABTS & 15 & 7 & 59.6 & 60.8 \\
\hline
\end{tabular}

Fig. 3 The antioxidant activity of control and marinated meat determined by DPPH assay
According to the DPPH assay of extract, $p$ value obtained from analysis was $(P>0.005)$ showed effective antioxidant since the value obtained was 0.053 still in significant.

ABTS of sample was obtained at day three, day six and day nine. Figure 4 was the triplicate reading of marinated sample, control sample and average value obtained from marinated sample. Measurement was expressed as absorbance and decreasing value absorbance indicated increasing the antioxidant activity. Previous study reported that higher ABTS radical scavenging activity was found in hydrophilic than hydrophobic extract, while another study stated that instead of ABTS, DPPH analysis was limited to interpreted hydrophobic antioxidant. Hence, it could be possible that the antioxidant present in $P$. edulis peels possess more lipophilic in nature $[27,38]$.

Scavenging the ABTS radical by the $P$. edulis peels was found to be much higher than that of DPPH radical at all day. These differences can be explained by the mechanism of the involved reaction. The ABTS radical reactions involve electron transfer and take place at a much faster rate compared to DPPH radicals [26, 39, 40]. Meanwhile, ABTS analysis obtained $(P<0.005)$, but also in significant because the value was 0.047 . Table 4 shows the percentage of DPPH and ABTS free radical scavenging activity in 9 days analysis was around $60.8 \%$.

\subsection{Reducing power assay}

Reducing power assay was a convenient and rapid screening method for measuring the antioxidant potential [41]. The presence of antioxidant in meat causes the reduction of Ferric cyanide complex to ferrous form, therefore the ferrous iron complex could be observed by measuring the formation of Perl's Prussian blue powder like. Figure 5 showed the percentage that increased absorbance of the reaction mixture indicated increased reducing power and antioxidant activity. Analysis of ANOVA on this test

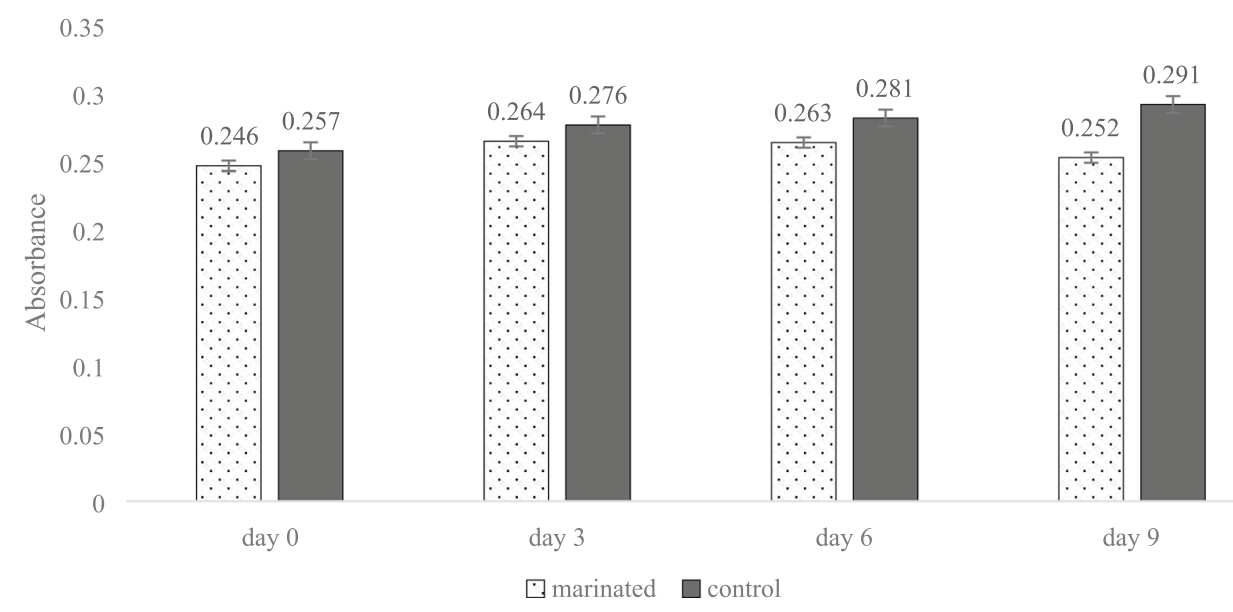

SN Applied Sciences A SPRINGER NATURE journal 
Fig. 4 The radical scavenging activity of control and marinated meat determined by ABTS assay

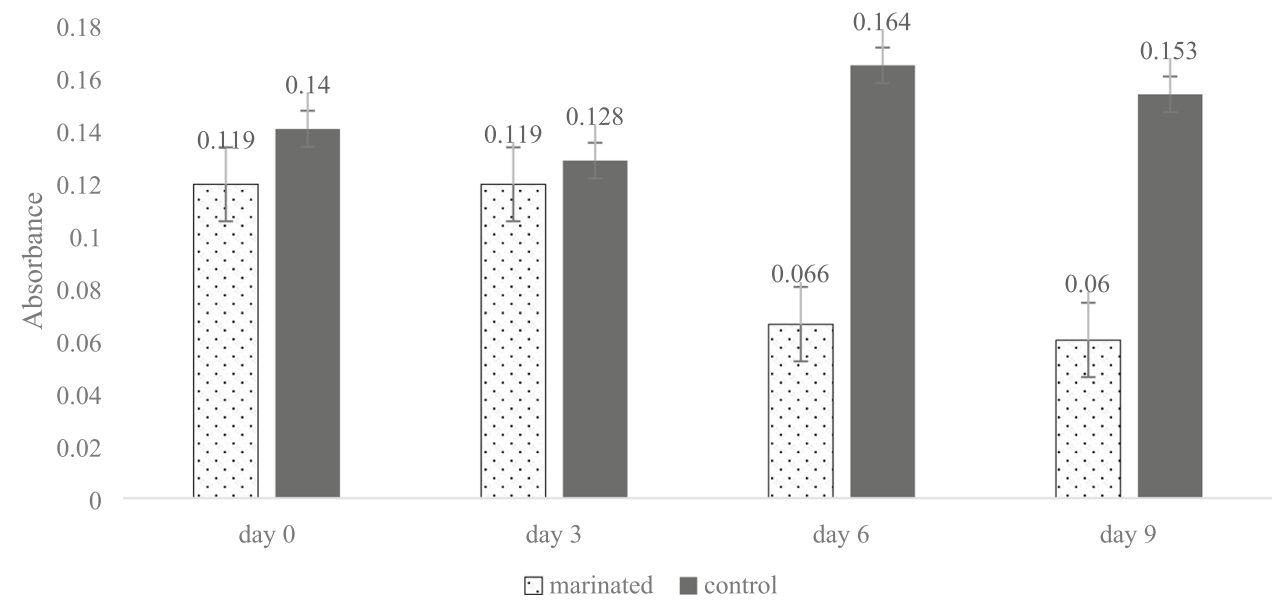

obtained $(P>0.05)$ which was 0.0511 . Reducing power assay is a convenient and rapid screening method for measuring the antioxidant potential [38]. The potassium ferric cyanide reduction measures the color change of the test solution from yellow to various shades of green and blue depending upon the reducing power of each sample. The presence of antioxidant in meat causes the reduction of Ferric cyanide complex to ferrous form, therefore the ferrous iron complex could be observed by measuring the formation of Perl's Prussian blue powder like observed at $700 \mathrm{~nm}$. Figure 5 showed the absorbance reading obtained for 9 days. Mean value for marinated sample and control for all 9 days was around the 0.100 ranged and not exceeding to 0.200 . From Fig. 5, the mean absorbance for marinated sample from day zero 0.063 was increased slightly into 0.113 at day nine.

Previous studies reported that compounds with reducing power indicate that they were electron donors and could reduce the oxidized intermediates of lipid peroxidation processes, so that they could act as primary and secondary antioxidants $[10,27,42]$.

Fig. 5 The antioxidant potential of control and marinated meat determined by reducing power assay

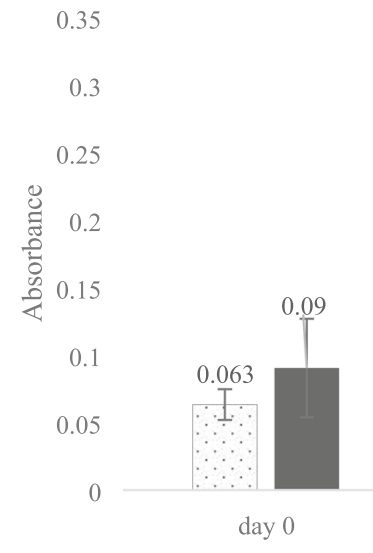

power assay
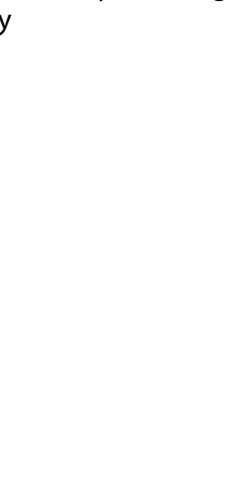

\subsection{Measurement of metmyoglobin}

According to the metmyoglobin assay of meat marinated with extract produce $(P>0.05)$ which is 0.0598 . The highest amount of metmyoglobin was observed in the marinated meat sample with peel extract at the end of storage as shown in Fig. 6.

The color or red meat was one of the important factor or characteristics of its freshness and its quality. The reduction of red color by formation of metmyoglobin in brown color indicated proportional to the oxidative degradation in meat throughout storage time [35]. The higher absorbance at $503 \mathrm{~nm}$ may have been due to the natural color in light yellow [43].

The amount of metmyoglobin has been positively linked to the extent of protein oxidation in meat products (Fig. 7). Metmyoglobin content increased during storage. The lowest increasing rate was observed in the control samples. The highest amount of metmyoglobin was observed in the marinated meat sample with peel extract at the end of storage. From Fig. 6 shows that after 9 days, the value of absorbance reading decrease to 0.104 lower

\footnotetext{
SN Applied Sciences 
Fig. 6 The Metmyoglobin assay for control and marinated meat samples

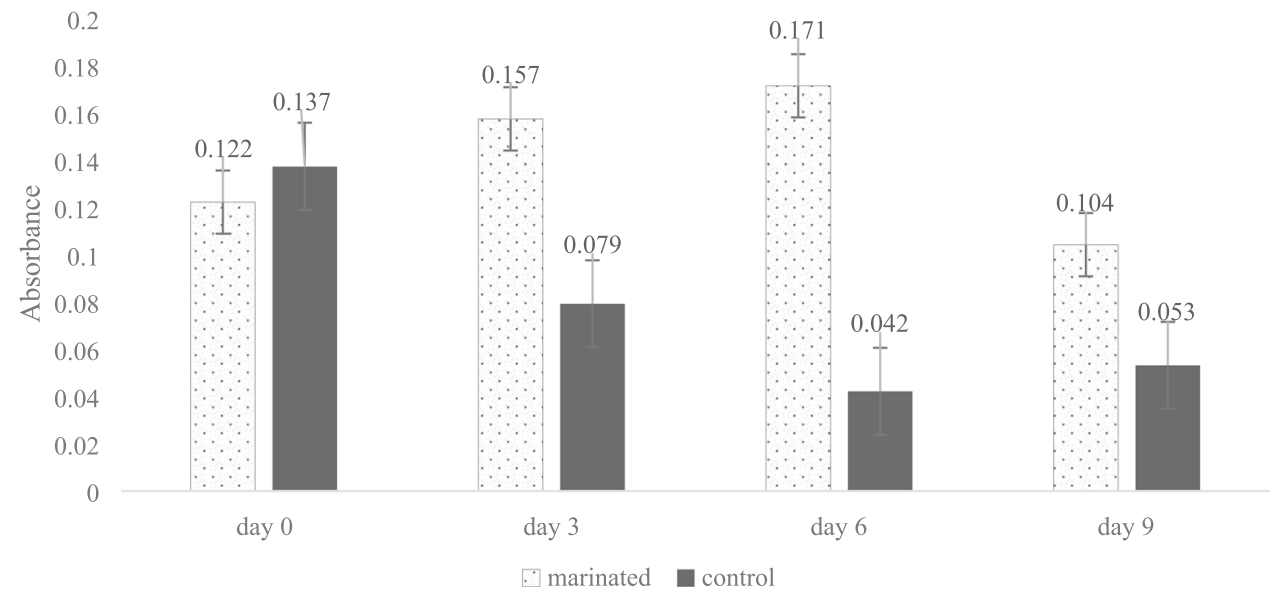

than initial reading on day 0 . This may due to the no more antioxidant activity of peel extract on meat.

\section{7 pH determination}

The $\mathrm{pH}$ of marinated meat sample was significantly $(P>0.05)$ which was 0.389 since the $\mathrm{pH}$ value is lower than control meat sample along 9 days of analysis. The value of $\mathrm{pH}$ over 6.2 would indicate that the meat was ready for immediate consumption or at a critical limit for consumption, but marinated meat sample shows not required immediate consumption. From Fig. 8, initial pH value for control was not vary with marinated sample. The $\mathrm{pH}$ of marinated sample at day 3 was lower than control sample with 5.74 for marinated and 6.06 for control. After 6 days, at day 9 the $\mathrm{pH}$ for control sample slightly decrease to 6.26 and close to the $\mathrm{pH}$ value of marinated sample which was 5.79. However, $\mathrm{pH}$ value of marinated sample continuously increased from day 3 until day 9 . Based on all 9 days, the
$\mathrm{pH}$ value for control sample was seem fluctuation from day 0 until day 9 .

Previous study reported that the $\mathrm{pH}$ influences the capacity to retain water, loss of weight in cooking and shear force, as well as sensorial properties such as tenderness, juiciness, flavour, aroma and colour [14]. The $\mathrm{pH}$ values found indicated that meat homogenized with passion fruit peel were good quality, since $\mathrm{pH}$ values over 6.2 would indicate that the meat was ready for immediate consumption or at a critical limit for consumption.

\section{Conclusion}

Total phenolic and flavonoid content analysis in this study proved that sample extract from $P$. edulis peels contains antioxidant compound such as Meliadanoside A from phenolic group and 7-Hydroxy-5,3,4,'-trimethoxy flavone from flavonoid group. In details, all identified compound has been recognized by LC-QTOF-MS analysis. The effectiveness of

Fig. 7 Color of marinated meat sample and control meat sample at day 9
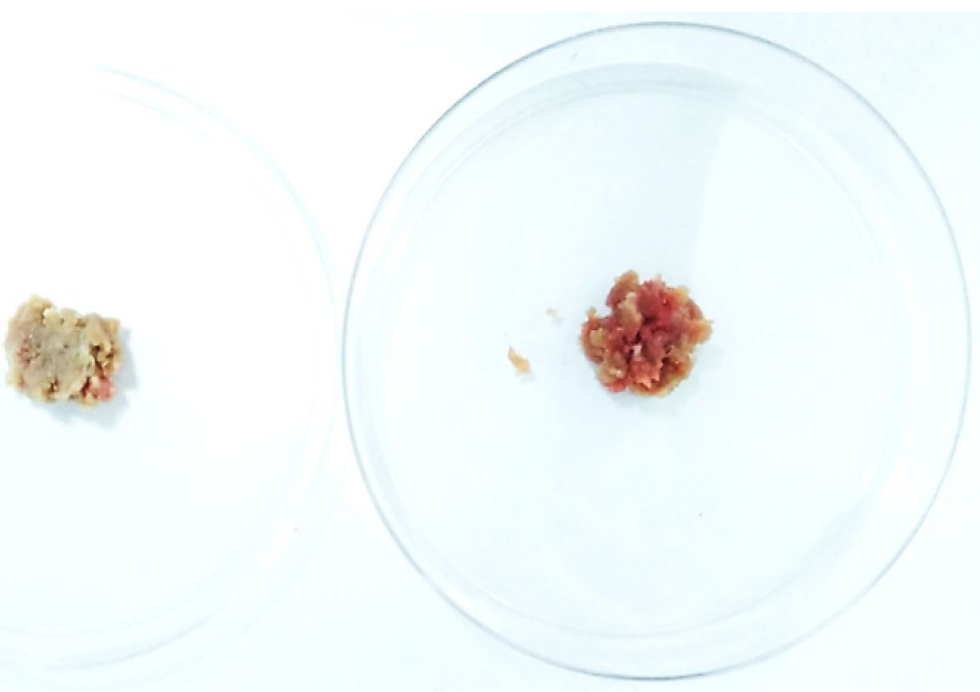
Fig. 8 The standard error bar for $\mathrm{pH}$ of meat sample

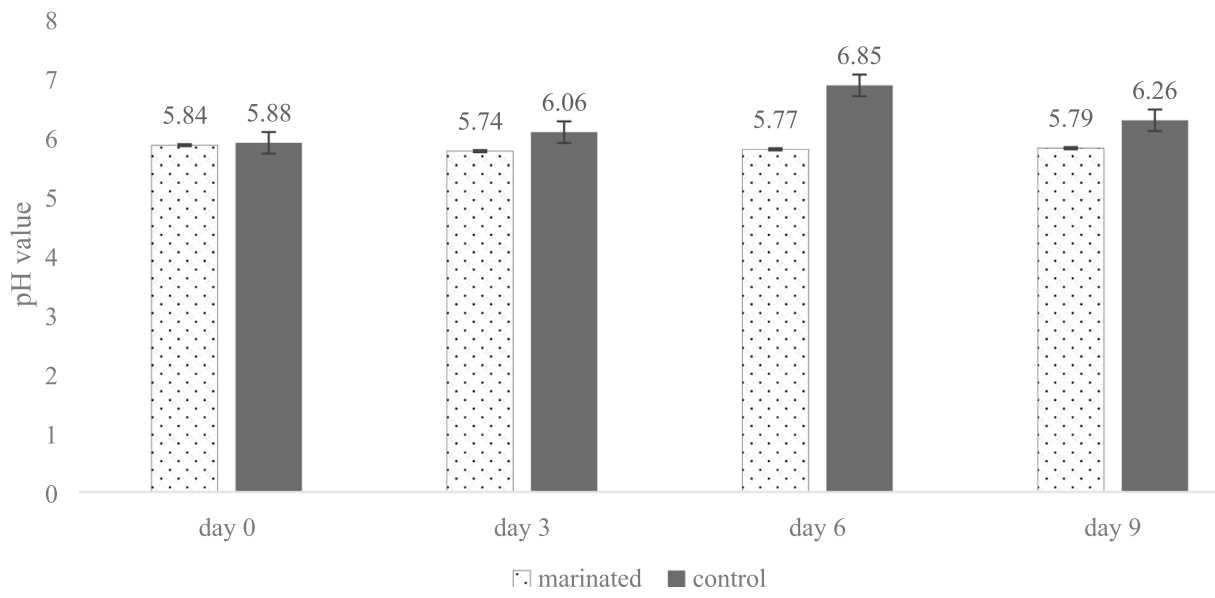

sample extract is determined by increasing in percentage of DPPH scavenging activity. The DPPH and reducing power assay can be used to provide additional information regarding changes occur in meat sample [8]. The ABTS free radical scavenging activity in this study indicates the increased of antioxidant activity of $P$. edulis peel extract. The reduction of red colour by formation of metmyoglobin in brown colour shows that the meat colour is one of the important factor or characteristics of its freshness and its quality. Extract of $P$. edulis peels shows the effectiveness on antibacterial activity since the formation of inhibition zone on plate that containing foodborne bacterial which is Aureus, Serratia, E. coli and Vulgaris. The extract obtained from Passiflora edulis may be used, by the food industry in general and meat industry in particular as potential natural addictive to replace the synthetic ones since it shows the significant antioxidant and antibacterial properties throughout several test.

Acknowledgements The authors gratefully acknowledged Universiti Malaysia Pahang for the financial assistance through the Internal Research Grant Nos. RDU190331 and RDU190122.

\section{Compliance with ethical standards}

Conflict of interest There are no conflicts to declare.

\section{References}

1. Shah MA, Bosco SJD, Mir SA (2014) Plant extracts as natural antioxidants in meat and meat products. Meat Sci 98:21-33. https ://doi.org/10.1016/j.meatsci.2014.03.020

2. Hopkins DL, Clayton EH, Lamb TA et al (2014) The impact of supplementing lambs with algae on growth, meat traits and oxidative status. Meat Sci 98:135-141. https://doi.org/10.1016/j.meats ci.2014.05.016

3. Shahidi $F$ (2016) Oxidative stability and shelf life of meat and meat products. Elsevier, Amsterdam

4. Holman BWB, Mao Y, Coombs CEO et al (2016) Relationship between colorimetric (instrumental) evaluation and consumer-defined beef colour acceptability. Meat Sci 121:104106. https://doi.org/10.1016/j.meatsci.2016.05.002

5. Devatkal SK, Thorat P, Manjunatha M (2014) Effect of vacuum packaging and pomegranate peel extract on quality aspects of ground goat meat and nuggets. J Food Sci Technol 51:26852691. https://doi.org/10.1007/s13197-012-0753-5

6. Lorenzo JM, Batlle R, Gómez M (2014) Extension of the shelf-life of foal meat with two antioxidant active packaging systems. LWT Food Sci Technol 59:181-188. https://doi.org/10.1016/j. Iwt.2014.04.061

7. Bhuyar P, Rahim MH, Sundararaju S, Maniam GP, Govindan $N$ (2020) Antioxidant and antibacterial activity of red seaweed; Kappaphycus alvarezii against pathogenic bacteria. Glob J Environ Sci Manag. https://doi.org/10.22034/gjesm.2020.01.0

8. Huang B, He J, Ban X et al (2011) Antioxidant activity of bovine and porcine meat treated with extracts from edible lotus (Nelumbo nucifera) rhizome knot and leaf. Meat Sci 87:46-53. https://doi.org/10.1016/j.meatsci.2010.09.001

9. Fernandes RPP, Trindade MA, Lorenzo JM, de Melo MP (2018) Assessment of the stability of sheep sausages with the addition of different concentrations of Origanum vulgare extract during storage. Meat Sci 137:244-257. https://doi.org/10.1016/j.meats ci.2017.11.018

10. Fernandes RPP, Trindade MA, Tonin FG et al (2016) Evaluation of antioxidant capacity of 13 plant extracts by three different methods: cluster analyses applied for selection of the natural extracts with higher antioxidant capacity to replace synthetic antioxidant in lamb burgers. J Food Sci Technol 53:451-460. https://doi.org/10.1007/s13197-015-1994-x

11. Fasseas MK, Mountzouris KC, Tarantilis PA et al (2008) Antioxidant activity in meat treated with oregano and sage essential oils. Food Chem 106:1188-1194. https://doi.org/10.1016/j. foodchem.2007.07.060

12. Martínez L, Cilla I, Beltrán JA, Roncalés $P$ (2007) Effect of illumination on the display life of fresh pork sausages packaged in modified atmosphere. Influence of the addition of rosemary, ascorbic acid and black pepper. Meat Sci 75:443-450. https:// doi.org/10.1016/j.meatsci.2006.07.021

13. Sebranek JG, Sewalt VJH, Robbins KL, Houser TA (2005) Comparison of a natural rosemary extract and $\mathrm{BHA} / \mathrm{BHT}$ for relative antioxidant effectiveness in pork sausage. Meat Sci 69:289296. https://doi.org/10.1016/j.meatsci.2004.07.010

14. Bañón S, Díaz P, Rodríguez M et al (2007) Ascorbate, green tea and grape seed extracts increase the shelf life of low sulphite beef patties. Meat Sci 77:626-633. https://doi.org/10.1016/j. meatsci.2007.05.015 
15. Singh N, Rajini PS (2008) Antioxidant-mediated protective effect of potato peel extract in erythrocytes against oxidative damage. Chem Biol Interact 173:97-104. https://doi. org/10.1016/j.cbi.2008.03.008

16. Bampidis VA, Robinson PH (2006) Citrus by-products as ruminant feeds: a review. Anim Feed Sci Technol 128:175-217. https://doi.org/10.1016/j.anifeedsci.2005.12.002

17. Eim VS, Simal S, Rosselló C, Femenia A (2008) Effects of addition of carrot dietary fibre on the ripening process of a dry fermented sausage (sobrassada). Meat Sci 80:173-182. https ://doi.org/10.1016/j.meatsci.2007.11.017

18. Tomovi V (2017) Plants as natural antioxidants for meat products.pdf

19. Malacrida CR, Jorge N (2012) Yellow passion fruit seed oil (Passiflora edulis f. flavicarpa): physical and chemical characteristics. Braz Arch Biol Technol 55:127-134. https://doi. org/10.1590/S1516-89132012000100016

20. Hernández-Santos B, de los Ángeles Vivar-Vera M, RodríguezMiranda J et al (2015) Dietary fibre and antioxidant compounds in passion fruit (Passiflora edulis f. flavicarpa) peel and depectinised peel waste. Int J Food Sci Technol 50:268-274. https://doi.org/10.1111/ijfs.12647

21. López-vargas JH, Fernández-lópez J, Pérez-álvarez JA, Viudamartos M (2013) Chemical, physico-chemical, technological, antibacterial and antioxidant properties of dietary fi ber powder obtained from yellow passion fruit (Passiflora edulis var. fl avicarpa) co-products. FRIN 51:756-763. https://doi. org/10.1016/j.foodres.2013.01.055

22. He X, Luan F, Yang Y et al (2020) Passiflora edulis: an insight into current researches on phytochemistry and pharmacology. Front Pharmacol 11:1-16. https://doi.org/10.3389/fphar .2020 .00617

23. Oliveira DA, Angonese M, Ferreira SRS, Gomes L (2017) Food and bioproducts processing nanoencapsulation of passion fruit by-products extracts for enhanced antimicrobial activity. Food Bioprod Process 104:137-146. https://doi.org/10.1016/j. fbp.2017.05.009

24. Reveny J, Ginting H (2018) Antioxidant test, phenolic and flavonoid content ethanol extract and ethyl acetate fraction of purple passion fruit peel (Passiflora edulis Sims.). 9:86-91.

25. Wong YS, Sia CM, Khoo HE et al (2014) Influence of extraction conditions on antioxidant properties of passion fruit (Passiflora edulis) peel. Acta Sci Pol Technol Aliment 13:257-265. https://doi.org/10.17306/J.AFS.2014.3.4

26. Bhuyar P, Sundararaju S, Ab. Rahim MH, Ramaraj R, Maniam GP, Govindan N (2019) Microalgae cultivation using palm oil mill effluent as growth medium for lipid production with the effect of $\mathrm{CO}_{2}$ supply and light intensity. Biomass Convers Biorefin. https://doi.org/10.1007/s13399-019-00548-5

27. Ballester-Costa C, Sendra E, Fernández-López J, Pérez-Álvarez JA, Viuda-Martos M (2017) Assessment of antioxidant and antibacterial properties on meat homogenates of essential oils obtained from four thymus species achieved from organic growth. Foods 6:59. https://doi.org/10.3390/foods6080059

28. Bhuyar P, Sathyavathi S, Math RK (2020) Production of bioethanol from starchy tuber (Amorphophallus commutatus) and antimicrobial activity study of its extracts. Afr J Biol Sci 2:7076. https://doi.org/10.33472/AFJBS.2.2.2020.70-76

29. Bhuyar P, Yusoff MM, Rahim MHA, Sundararaju S, Maniam GP, Govindan N (2020) Effect of plant hormones on the production of biomass and lipid extraction for biodiesel production from microalgae Chlorella Sp. J Microbiol Biotechnol Food Sci 9(4):671-674. https://doi.org/10.15414/jmbfs .2020.9.4.671-674
30. Khammee $P$, Ramaraj R, Whangchai $N$ et al (2020) The immobilization of yeast for fermentation of macroalgae Rhizoclonium sp. for efficient conversion into bioethanol. Biomass Conv Bioref. https://doi.org/10.1007/s13399-020-00786-y

31. Bhuyar P, Rahim MHA, Sundararaju S et al (2020) Synthesis of silver nanoparticles using marine macroalgae Padina sp. and its antibacterial activity towards pathogenic bacteria. Beni-Suef Univ J Basic Appl Sci. https://doi.org/10.1186/s4308 8-019-0031-y

32. Tian D, Shen F, Yang $G$ et al (2019) Liquid hot water extraction followed by mechanical extrusion as a chemical-free pretreatment approach for cellulosic ethanol production from rigid hardwood. Fuel 252:589-597. https://doi.org/10.1016/j. fuel.2019.04.155

33. Khammee $P$, Ramaraj $R$, Whangchai $\mathrm{N}$ et al (2020) The immobilization of yeast for fermentation of macroalgae Rhizoclonium sp. for efficient conversion into bioethanol. Biomass Convers Biorefin. https://doi.org/10.1007/s13399-020-00786-y

34. Ahmad MS, Cheng CK, Bhuyar P et al (2021) Effect of reaction conditions on the lifetime of SAPO-34 catalysts in methanol to olefins process-a review. Fuel. https://doi.org/10.1016/j. fuel.2020.118851

35. Bekhit AED, Geesink GH, Ilian MA et al (2003) The effects of natural antioxidants on oxidative processes and metmyoglobin reducing activity in beef patties. Food Chem 81:175-187. https://doi.org/10.1016/S0308-8146(02)00410-7

36. Park KB (2009) Microbiology legend cycle 41 organism 3 Proteus vulgaris $27: 1-3$

37. Garcia EJ, De AS, Reis A et al (2012) Antioxidant activity by DPPH assay of potential solutions to be applied on bleached teeth. Braz Dent J 23:22-27

38. Sultana K, Jayathilakan K, Pandey MC (2017) Evaluation of antioxidant activity, radical scavenging, and reducing power of clove oil and clove oleoresin in comparison with natural and synthetic antioxidants in Chevon (Capra aegagrus hircus) and chicken meat. Def Life Sci J 3:51. https://doi.org/10.14429 /dlsj.3.12016

39. Saengsawang B, Bhuyar P, Manmai N, Ponnusamy VK, Ramaraja $\mathrm{R}$, Unpaprom $\mathrm{Y}$ (2020) The optimization of oil extraction from macroalgae, Rhizoclonium sp. by chemical methods for efficient conversion into biodiesel. Fuel 274:117841. https://doi. org/10.1016/j.fuel.2020.117841

40. Zhang L, Tu Z, Xie X et al (2017) Jackfruit (Artocarpus heterophyllus Lam.) peel: a better source of antioxidants and a-glucosidase inhibitors than pulp, flake and seed, and phytochemical profile by HPLC-QTOF-MS/MS. Food Chem 234:303-313. https://doi.org/10.1016/j.foodchem.2017.05.003

41. Bagul MS, Rajani M, Parabia M (2008) Scientific publication of the Indian Pharmaceutical Association synthesis, antimicrobial and antiinflammatory activity. Indian J Pharm Sci 70:31

42. Gupta D, Mann S, Sood A, Gupta RK (2011) Phytochemical, nutritional and antioxidant activity evaluation of seeds of jackfruit (Artocarpous heterolphyllus Lam.). Int J Pharma Bio Sci 2:336-345

43. Mancini RA, Hunt MC (2005) Current research in meat color. Meat Sci 71:100-121. https://doi.org/10.1016/j.meatsci.2005.03.003

Publisher's Note Springer Nature remains neutral with regard to jurisdictional claims in published maps and institutional affiliations. 